Les intellectuels en Espagne, de la dictature à la démocratie (1939-1986)

\title{
Aurora Bosch, Teresa Carnero, Sergio Valero (eds.), Entre la reforma y la revolución. La construcción de la democracia desde la izquierda
}

Paul Aubert

\section{OpenEdition}

\section{Journals}

Edición electrónica

URL: http://journals.openedition.org/bhce/928

DOI: $10.4000 /$ bhce.928

ISSN: 1968-3723

Editor

Presses Universitaires de Provence

Edición impresa

Fecha de publicación: 1 diciembre 2016

Paginación: 313-320

ISSN: 0987-4135

Referencia electrónica

Paul Aubert, « Aurora Bosch, Teresa Carnero, Sergio Valero (eds.), Entre la reforma y la revolución. La construcción de la democracia desde la izquierda », Bulletin d'Histoire Contemporaine de l'Espagne [En línea], 50 | 2016, Publicado el 09 octubre 2018, consultado el 24 septiembre 2020. URL : http:// journals.openedition.org/bhce/928; DOI : https://doi.org/10.4000/bhce.928 
su participación en la vida política de los republicanos exiliados, su papel en los inicios de la unificación europea, etc.

La política como pasión es una biografía seria, rigurosa y bien documentada. Explica los porqués de la vida del lehendakari José Antonio Aguirre atendiendo al cambiante contexto que le tocó en suerte, al que se adaptó y que, en no pocas ocasiones, él mismo contribuyó a modificar en un sentido u otro. Se trata de una obra de alta divulgación que está escrita con el evidente propósito de llegar a un público amplio: el estilo es ameno y las notas a pie de página han sido reducidas considerablemente. Tal vez en alguno de los primeros capítulos se trasluce una simpatía por el personaje demasiado evidente, pero, en general, se ha adoptado un punto de vista mesurado: también se resaltan los errores y defectos del biografiado, desmitificando la heroica aureola que a veces se le ha conferido. En definitiva, La política como pasión es una obra imprescindible para conocer la trayectoria de uno de los mayores protagonistas de la historia reciente del País Vasco.

Gaizka FERNÁNDEZ SOLDEVILLA IES Marqués de Manzanedo (Santoña)

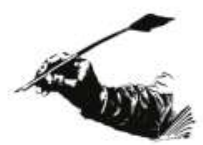

\section{Aurora BOSCH, Teresa CARNERO, Sergio VALERO (eds.)}

Entre la reforma y la revolución. La construcción de la democracia desde la izquierda, Granada, Comares, 2013, 304 p.

El título del libro parece formular una evidencia: la democracia, como el progreso, sería de izquierdas. El historicismo acepta mal que unos revolucionarios puedan proclamar que alcanzaron sus objetivos. Pero el conservadurismo español no se alejó siempre de los nostálgicos del Antiguo Régimen y el liberalismo se apresuró a corregir su atrevimiento y redujo el cuerpo electoral acogiéndose al liberalismo doctrinario que imperaba también en el resto de la Europa liberal. No obstante, el presidente de la II República, Niceto Alcalá Zamora, estuvo preocupado por encontrar una derecha republicana capaz de alternar con la izquierda, sugiriendo que la democracia puede ser la reforma pero en ningún caso la revolución, aunque a la sazón podían confundirse, a causa de la intransigencia de quienes consideraban que el cambio de régimen era ya en sí una revolución. No cabe duda de que la dimisión de Miguel Maura, quien acabará pidiendo en 1936 un gobierno autoritario, contribuyó al desequilibrio del espectro político republicano propiciando sin duda la emergencia del partido de Lerroux. Sobre el particular, el prólogo de Aurora Bosch es de un rigor ejemplar. El libro, fruto de un programa de investigación del ministerio de Economía y Competitividad cuyo fin era llevar a cabo un estudio comparado del desarrollo democrático entre España y otros países europeos o norteamericanos, está dividido en cinco apartados que estudian la evolución del proceso democrático en Europa y América, considerando que éste nunca fue de corta duración: Socialismo, democracia y nación, Juventud, izquierda y democracia, República, democracia y transición desde las identidades de género, Anarquismo y democracia en el primer tercio del siglo XX. Izquierda y democracia desde Francia y América. 
El capítulo introductorio de Teresa Carnero Abat, que reflexiona sobre el ciclo de democratización del Estado en España, enfoca la cuestión con el distanciamiento y la ambición necesarios, ofreciendo una conceptualización interesante. Se refiere a la autocracia parlamentaria y al liberalismo sin democracia de la Restauración y a la cuestión de las élites, antiguas y nuevas, frente al problema nacional, que no supieron o no pudieron contemplar la posibilidad de alcanzar una ciudadanía política igualitaria. Fracasaron en su intento de pasar dignamente del sistema político liberal doctrinario a la democracia. Aludiendo a los ritmos del proceso de democratización, para evaluar este proceso de integración, Teresa Carnero propone estudiar la evolución constitucional y sobre todo la de las leyes electorales. Jugar con el cuerpo electoral fue la principal modalidad encontrada, de nuevo, para salir dignamente del liberalismo doctrinario. La cuestión de la transparencia del sufragio, que reconoce a cada grupo o individuo la posibilidad de acceder en condiciones de igualdad al sufragio y aspirar a formar parte de la élite, es, con la universalidad del mismo, la pauta que permite asemejar voto femenino y democratización. La otra cuestión es la libre competencia entre las distintas opciones políticas y la ausencia de control o de filtración de las candidaturas, es decir, más allá de la legitimación del adversario, la organización de elecciones limpias. Queda otro enfoque, y no es el de este libro, el del espacio otorgado a las aspiraciones regionalistas o nacionalistas que apareció, lo mismo que el voto femenino, como una señal de democracia superior.

Fernando del Rey Reguillo reflexiona en torno a «Socialismo y democracia en la España de entreguerras (notas para une historia comparada)» a partir de un estudio de la cultura política de este movimiento en Europa - uno de los que mejor se ajustan a la temática de la obra- distinguiendo entre «socialismo sindical» (Besteiro), «socialismo político» (Prieto) y «socialismo radical» (Largo Caballero), es decir desde el ala más moderada hasta la revolucionaria, para introducir matizaciones según las coyunturas, en particular tras la presencia de Largo Caballero en el Consejo de Estado de Primo de Rivera que explica en parte ciertas reticencias socialistas frente al Pacto de San Sebastián. El autor de este artículo muestra bien cómo la etapa posterior confronta, a lo largo del primer bienio, el socialismo español con la democracia y el parlamentarismo e incluso con la construcción del nuevo régimen republicano. La radicalización que sigue contra lo que se les antoja a los más revolucionarios «una república burguesa» no impide que el candidato más votado en Madrid cuando las elecciones de noviembre de 1933 sea Besteiro quien se oponía a esta línea. La Guerra civil y la derrota abrieron otra etapa y la democracia llegó a ser a la vez un recuerdo y una esperanza. La Guerra fría acabó con cualquier veleidad revolucionaria. La mirada a Europa que sigue esta evaluación de la ideología socialista española, permite comprobar el compromiso de los socialistas, con la excepción de Francia donde el movimiento estuvo más dividido, con las formas parlamentarias hasta en aquellos países nórdicos que eran monarquías. Al pasar de la lucha de clases a la defensa del Estado providencia (según la expresión de Iring Fetscher citada), en unos países donde les había impactado más la revolución rusa (Suecia, Noruega, Dinamarca) y carecían de experiencia de gobierno, los socialistas protagonizaron coaliciones que explican la estabilidad de sus gobiernos y el hecho de hayan preferido la democracia a la hipótesis revolucionaria. Esta óptica comparada le permite a Fernando de Rey, cuando recuerda que la radicalización del PSOE es anterior a la derrota austriaca, comprobar también que el fascismo no cuajó en España en los años anteriores a la Guerra civil y que la movilización del mundo católico contra la República fue más un mito movilizador o una justificación a posteriori de su estrategia insurreccional que una amenaza fascista. La CEDA representaba de hecho la 
reunión de los enemigos tradicionales del PSOE y de la República : los terratenientes y los patronos, la Iglesia y el Ejército. La sociedad estaba poco preparada para el ejercicio democrático. ¿Pensó algún día Gil Robles encarnar una derecha republicana capaz de alternar en el poder con la coalición republicano-socialista? ¿Se hubieran contentado los socialistas con una democracia burguesa? Tampoco se pueden menoscabar los errores y las limitaciones ideológicas de algunos de sus líderes a la hora de asumir un deslucimiento y unas tensiones mayores que los de sus homólogos europeos.

Al estudiar el discurso de la nación en Leviatán, órgano de la tendencia bolchevizante del PSOE, más preocupado por la Revolución rusa que por el discurso nacional, Aurelio Martí Bataller quiere mostrar que los socialistas, por internacionalistas que fueran, no sólo no habían renunciado a la nación sino que alimentaban el discurso nacionalista. Peca sin duda de optimista pretendiendo, tras «un breve recorrido histórico», que los intelectuales se dedicaron principalmente a la producción de este discurso porque si tal discurso existiera no se hubiera preguntado cada promoción en qué consistía. Es sin duda una cuestión de enfoque: la insistencia revela a menudo un fracaso reiterado más que una riqueza ideológica. Hubiera sido interesante, si el fin era estudiar la evolución de un discurso, rastrear la expresión de esta ideología nacional desde las demás publicaciones socialistas, Nosotros, Post-guerra, Nueva cultura, España Nueva, La Antorcha, nacidas en la coyuntura republicana e incluso partir de La Nueva Era (1901), en vez de contentarse con una serie de definiciones ajenas, o con la glosa de Antonio Ramos Oliveira. El autor distingue tres temas: el anticlericalismo y la identidad nacional, el hispanoamericanismo y el pueblo. Pero olvida que a Araquistaín se debe uno de los primeros comentarios de la Revolución mejicana en la que ve una referencia para España. Una mayor atención prestada a la bibliografía sobre este autor, desde los estudios de Mercedes Cabrera hasta los de Juan Francisco Fuentes, le hubiera ayudado a contextualizar el propósito y a matizar algunas afirmaciones. Pues la reiteración de la hipótesis inicial en conclusión no vale demostración. Y quizá sea apresurado concluir que «por estos caminos cabría encontrar el origen del nacionalismo obrero esbozado durante la Guerra civil». ¿Existe tal nacionalismo que el autor parece confundir con el patriotismo? Concluye el trabajo un demasiado breve análisis formal, rudimentario, que consiste en contrastar la parquedad metafórica de Azaña comprobada por Araquistaín al lirismo del escritor socialista al hablar de España, cuando ya el análisis del discurso político y de los conceptos ha producido obras importantes, desde Régine Robin o Jacques Guilhaumou, en Québec y en Francia, hasta Antonio Rodríguez de las Heras y sobre todo Javier Fernández Sebastián, en España.

Tres estudios están dedicados a los movimientos juveniles. Al interesarse por las juventudes obreras en la Europa de entreguerras, Sandra Souto Kustrín vuelve sobre una historia que ella misma contribuyó a estructurar en aportaciones anteriores. Estas juventudes oscilaron entre la democracia y la dictadura del proletariado movidas por un antifascismo militante y acogiéndose a veces a una referencia frentepopulista. Recordando la noción de vanguardia o de vanguardismo en la lucha por la dictadura del proletariado, que brotó de la actuación de dichas juventudes socialistas frente al paternalismo vigente en los años anteriores dentro del movimiento obrero que pretendía mantener sus organizaciones juveniles en las tareas educativas o culturales para evitar roces que desembocarían en la escisión de los partidos comunistas. Lo que estaba en juego, y no le había escapado a Lenin, era la capacidad de tales juventudes a independizarse. Lo que lograron brevemente antes de verse absorbidas de nuevo por la internacional. El intento de crear una Internacional Juvenil Comunista sucumbió con la necesidad de someterse a la dirección de los partidos, hasta que 
se aprovecharon de la participación de varios partidos socialistas en el poder antes de verse golpeadas por la crisis de 1929 y atraídas por la URSS y el proceso de bolchevización de las juventudes socialistas que afecta a muchos países europeos. Pero ¿podían acertar estas juventudes donde estaban fracasando sus mayores?

En España, hasta las elecciones de noviembre de 1933, el comunismo era prácticamente inexistente. Después de octubre de 1934, el socialismo, que había intentado hacer la revolución, no fue el mismo. Sergio Valero Gómez muestra, estudiando la radicalización de la Federación Socialista Valenciana, cómo la unificación de la izquierda del PSOE y de los comunistas acabó imponiéndose. El pacto con los republicanos, dentro de un sistema burgués, no correspondía a las esperanzas de la izquierda radicalizada que tuvo sin embargo que aceptar en breve la estrategia del Frente popular. Pero con la Guerra, el PCE adapta mejor sus planes a las condiciones creadas por la guerra y se beneficia de la ayuda de la URSS, mientras el PSOE no acepta adhesiones de última hora a sus organizaciones. Los roces entre el ala largocaballerista del PSOE y la comunista es patente en el seno de la sección valenciana de las Juventudes Socialistas donde Segundo Serrano Poncela, Enrique Cerezo etc. creen que ésta debe encarnar la vanguardia juvenil del cambio revolucionario. Cuando Santiago Carrillo anuncia, en diciembre de 1936, que las Juventudes Socialistas Unificadas deben transformarse en amplio movimiento juvenil antifascista sin distinción ideológica, el ala caballerista se niega a renunciar al referente marxista y al control organizativo. $Y$ en marzo de 1937, cuando Carrillo declara que las JSU habían pasado al ámbito comunista, la discrepancia de la dirección valenciana, que vuelve a asumir sus preferencias caballeristas, es patente, como lo ilustra la aparición de «Rincones Largo Caballero » por la capital valenciana con el fin de «ser educadores y formadores de marxistas» aunque tengan que oponerse a la Ejecutiva nacional. Tampoco puede olvidarse el derrotismo que llevó en marzo de 1939 ciertas instancias del movimiento socialista a adherirse a la iniciativa del coronel Casado mientras se oían voces que lamentaban la disolución de las Juventudes Socialistas Unificadas y su unión a las Juventudes Comunistas hasta lograr la restauración de una Federación Nacional de Juventudes Socialistas de España y, en algunas capitales como Valencia, el anuncio de la expulsión de quienes habían sido los dirigentes de las JSU.

Marc Baldó Lacomba recuerda la importancia que tuvieron los movimientos estudiantiles en la lucha antifranquista y en qué medida constituyeron un espacio de debate que propició la participación de los estudiantes en la política. Enfoca su estudio desde un punto de vista demográfico (el baby boom de la posguerra) y sociológico (son los hijos de las clases medias), pero también comprueba que el ámbito de dicha rebelión es mundial y corresponde pues a una reacción contra la estandarización cultural de la sociedad de masas y la extensión del modelo del Estado de Bienestar o del Estado protector franquista, que no pueden confundirse. Pero este marco referencial no agota el espectro ideológico de dichos movimientos - pues Tierno Galván no era Jean-Paul Sartre y sería sin duda vano querer definir el sesentayochismo- aunque pudieron ser permeables a muchas influencias, desde el discurso feminista de Simone de Beauvoir o los movimientos pro derechos civiles norteamericanos, hasta un marxismo plural, la nueva izquierda o la ecología. Y en España la protesta estudiantil, que fue plural y recibió inicialmente pocos apoyos, llegó a ser una de las mayores manifestaciones de la oposición al franquismo. La lucha fue en buena medida cultural, pues no se podía ignorar el mundo exterior cuando el régimen franquista difícilmente aceptaba intentos aperturistas y respondía con la prohibición de actos culturales. En España, el movimiento estudiantil no tenía como fin reformar la universidad sino acabar con el régimen franquista y finalmente aspiraba a encarnar una vanguardia política. 
Tres contribuciones consideran la situación de la mujer desde la II República hasta la transición a la democracia, analizando ciertas circunstancias propias al País valenciano. Si la satisfacción de la reivindicación feminista apareció a menudo, tras el logro de la reforma educativa para alcanzar la ciudadanía, como una forma de democracia superior, la retórica republicana apuntaba también hacia una instrucción que preparara a la mujer a profesiones medias y superiores y contribuyera a la inculcación del laicismo en la educación de sus hijos. Desde las nuevos discursos pedagógicos institucionistas hasta las iniciativas republicanas, Luz Sanfeliu hace hincapié en la democratización de las prácticas educativas vinculadas al lerrouxismo y al blasquismo y consolidadas con la República en cuanto se quiso disponer de instituciones educativas capaces de contribuir al afianzamiento del espíritu republicano y de la democracia. Las experiencias pedagógicas no llegaron hasta la coeducación de los sexos - a la que se oponía la derecha-, fuera de las escuelas normales, y de los establecimientos vinculados a la Institución Libre de Enseñanza, pero el fin era reconocer a la mujer el disfrute de la ciudadanía.

A esta cuestión está dedicada precisamente la colaboración de Ana Aguado, quien estudia, tras dos breves retratos de María Cambrils y María Lejárraga, la construcción de una nueva identidad femenina desde el papel de la mujer en la cultura socialista. Esta presencia es importante para la extensión del feminismo en España, en un momento de lucha con las derechas católicas, porque, recuerda que el XI Congreso del PSOE, en octubre de 1918, reivindicó el sufragio universal, tanto femenino como masculino. Hubiera podido partir del $1^{\circ}$ de mayo de 1910 , para medir la evolución de las mentalidades y recordar la necesidad para la mujer de llevar a cabo una doble lucha, como militante política y como mujer, cuando al final del encuentro un futuro vocal del Comité nacional, Luis Pereira, dio rienda suelta a su angustia frente a tal ansia de emancipación femenina, preguntando: «¿Quién nos coserá los calcetines?». Lo cual explica que surjan voces femeninas que protestan contra la incomprensión de los compañeros. Pero las socialistas empezaron a dirigirse a la mujer en su condición de madre o mujer del obrero más que de trabajadora, cuando se trataba de darle acceso al espacio público. Pero, no se habían resuelto las tensiones entre género y ciudadanía para movilizar políticamente a las mujeres y éste se transformaba en "casa republicana», en hogar. La autora recalca la actitud de María Lajárraga en este proceso y es consciente de que, a pesar de las limitaciones de las mentalidades, éste constituye un primer paso hacia la ciudadanía.

Durante la Transición, el feminismo apareció asimismo como una forma de democracia superior. Vicenta Verdugo Martí, consciente de la ambigüedad original de este proceso, con una monarquía que es a la vez causa y consecuencia de la Transición, supera esta mención teleológica que hace hincapié en el logro institucional y oculta la influencia del discurso femenino, para interesarse por la importancia de éste en la definición de lo público y lo privado. Llega por fin a vislumbrar, dentro de una doble militancia (feminista y política) nuevos espacios de sociabilidad más allá de la mera celebración del día internacional de la mujer, el 8 de marzo, y de un activismo de urgencia alrededor de la defensa de casos concretos frente a acusaciones de adulterios o de delitos sexuales. No obstante, el feminismo más radical consideraba la política como el «último reducto de la virilidad» incapaz de resolver la relación de fuerzas entre los sexos. Y sobre todo, hacía hincapié, además de la reivindicación del libre uso de los anticonceptivos, del derecho al aborto y al divorcio, en la violencia de género, una cuestión de ámbito internacional. La autora recuerda que sin el movimiento feminista, que se debilitó tras la llegada de los socialistas al Poder, «la historia 
de la democratización española habría sido otra, ya que muchas de las reivindicaciones feministas nos constaban en las agendas de las élites políticas de aquellos momentos.»

Puede parecer sorprendente encontrar un apartado dedicado al anarquismo, un movimiento que rechazaba el juego político y la democracia (aunque nace de una crítica de las tesis liberales y en particular de una serie de artículos de Bakunin, «Lettres d'un démocrate», que denuncian, en 1864, el carácter inacabado de la Revolución francesa) y cuya dualidad en las tensiones entre la práctica del sindicalismo abierto y el carácter clandestino de grupos, que no habían renunciado a la acción directa, invalidaban cualquier asomo participativo. Javier Navarro estudia, hasta 1939, las manifestaciones de las culturas políticas del movimiento libertario español, que ilustran, como ideología y como movimiento, más allá del entramado asociativo, la heterogeneidad de éste. Confirma pues la pertinencia del recurso al plural operado últimamente por varios especialistas (Termes, Álvarez Junco, Paniagua, Barrios, Tavera, Vega, Gabriel, Herrerín, Casanova etc.). Encuentra pues, tras esta comprobación, el común denominador a estas tendencias en la lucha contra el Estado, como objetivo, y la acción directa, como práctica. Gérard Brey en su colaboración dedicada al «Antielectoralismo anarquista español: teoría y práctica (1870-1936)» analiza, e imagina a veces, frente a las elecciones organizadas por el Sexenio, la Restauración y la Segunda República, el impacto de dicha propaganda no participativa en las contiendas electorales hasta las elecciones de 1934, remitiendo a las conclusiones de Diego Caro Cancela en cuanto a la participación anarcosindicalista en las elecciones de febrero de 1936 que dieron la victoria al Frente popular; lo cual indicaría que el voto anarquista no se puede obviar, aunque los ejemplos aducidos en A Coruña o Barcelona no son más que esto, ejemplos. Esta diversidad de orientaciones es también la que estudia Oscar Freán, atento a la violencia en el movimiento libertario español, mostrando la contradicción entre los principios ácratas y la práctica de ciertos militantes, hasta el momento de la Guerra civil en que los pacifistas ya son muy minoritarios. Pero no se puede asimilar la Guerra civil de 1936 a la violencia de algunos anarquistas de finales del siglo XIX, ni a un contexto de violencia política, porque ilustra precisamente el fracaso de la política.

Vistas desde Francia y América, con un enfoque de media duración, la izquierda y la democracia, con dos colaboraciones dedicadas respectivamente al Partido comunista español durante el exilio en Francia y al Partido comunista francés abocado a la aceptación de un programa común de gobierno con los socialistas a partir de 1972, cobran otra dimensión. Por una parte, se entiende que no hay ningún modelo único de democracia y que la ciudadanía más que una definición jurídica es un largo combate que se inscribe, no obstante, en una tradición, lo que Aurora Bosch, en el epílogo, llama «capital social», aludiendo a la confianza que acaba generando el Estado.

Dos estudios explican la pérdida de influencia de los partidos comunistas español y francés en condiciones totalmente opuestas: tras una lucha antifranquista, por una parte, y cuando se estaba preparando la unión de las izquierdas en Francia, por otra. Natacha Lillo estudia el caso peculiar de la evolución del Partido Comunista Español en el exilio, sobre todo desde su ilegalización en Francia en 1950, en el contexto de la Guerra fría y de la Guerra de Corea, que lo pone de facto bajo la tutela del Partido comunista francés. Instalado en Francia con sus organizaciones tales como la Unión de Mujeres españolas, los Amigos de Mundo Obrero etc., el PCE tenía entonces unos diez mil militantes. Pasado el tiempo de la guerrilla en el suelo español, llegó el de los viajes clandestinos de Jorge Semprún a Madrid. Fundamentándose en una serie de entrevistas a distintos dirigentes, la autora describe la red organizativa del PCE, sus campañas antifranquistas y el apoyo a los presos. 
El resultado de las elecciones a las Cortes constituyentes, en 1977, en las que consiguió tan sólo un $9,33 \%$ de votos y 19 diputados, después de haber sido el principal partido que había combatido a Franco, explicitaba el anclaje histórico del PCE al antifranquismo y la pérdida de su protagonismo político.

Jean Vigneux muestra cómo la colaboración del partido comunista francés con los socialistas desde 1963 a 1978 acabó favoreciendo a éstos incluso tras la ruptura del programa común en 1977, aunque los comunistas franceses se distanciaran de Moscú tras la invasión de Checoslovaquia en 1968 y se unieran al emergente eurocomunismo. Este tipo de alianza nunca favoreció a los comunistas y sólo aceleró la mutación y la crisis del partido tras una nueva participación en la vida política con la necesidad de llevar a cabo una política o de secundar un programa que no se aprobaba totalmente.

De la difícil instauración de la social democracia en América latina (1980-2012) se ocupa Nuria Tabanera García en las tres últimas décadas. Tras las revoluciones (que engendraron unos 30 movimientos armados en todo el continente) y las contrarrevoluciones que implicaban un cambio mayor en la ciudadanía, y hasta el triunfo electoral de una nueva izquierda en la década de 2000 , la afirmación, el $1^{\circ}$ de mayo de 2008 , del presidente boliviano Evo Morales que «la crisis se resolverá por las urnas», es un alivio para los demócratas y parece postergar la amplia definición que daba, en enero de 1978, el general Videla del terrorista como «alguien que difunde ideas contrarias a la civilización occidental y cristiana», llamando de hecho a una nueva St-Barthélémy. Cuando se abre este tercer ciclo democrático en el continente que lleva al Poder una nueva izquierda, cabe distinguir, sin embargo, entre la social-demócrata, reformadora, y otra más populista atraída por la democracia participativa o plebiscitaria e irritada por la democracia representativa de cuño liberal. Estos últimos movimientos pueden derivar, como en el siglo anterior, hacia una reacción antipolítica y un amago de poder personal hostil a los errores del neoliberalismo. La novedad radica en la organización de una sociedad civil en redes de sociabilidad con demandas específicas y en el aumento de la participación social. Lo cual afianza la idea de la autora de que ya la izquierda en América latina es compatible con la democracia.

Aurora Bosch dedica un estudio a la evolución de la democracia en los Estados Unidos, comprobando que ésta propició una renovación constante de las élites. Enfoca su trabajo desde la tradición de la izquierda a partir del populismo de finales del siglo XIX hasta el New Deal. A lo largo de esta «edad de oro», hasta la aparición de un partido radical, la posterior ola anticomunista a mediados de los años cuarenta y los años sesenta en que las distintas fórmulas democráticas alcanzaron su madurez, lo que estuvo en juego fue el reconocimiento de los derechos civiles. El partido demócrata se interesaba por las minorías pero la Gran Sociedad no pasó de alianza electoral, mientras el partido republicano evolucionaba hacia un populismo conservador empujando a los demócratas hacia el elitismo. En España lo había advertido Azaña confesando su temor de que la izquierda llegara demasiado pronto al poder. Pero, ¿hay un buen momento para llegar al poder?

En un breve epílogo, Teresa Carnero Arbat, cuida de situar la democracia en la historia y no ya como sinónimo de constitución u horizonte que va huyendo siempre sin desaparecer nunca. Al leer esta historia de la democracia que proponen estos colegas, se cuestionarán desde la tiranía del comparativismo algunos enfoques o algunos temas elegidos. Es la ley de cualquier obra colectiva en la que cada lector, animado por la mirada nueva de sus investigaciones personales, encuentra debilidades y lagunas. Por ahora, no es muy arriesgado profetizar que este libro, desde este triple enfoque del socialismo, de la juventud y de la 
mujer, con estos dos contrapuntos que son el anarquismo y la izquierda vista desde Francia y América, será una pauta notable en la comprensión de la primera mitad del siglo XX.

Paul AUBERT

Aix-Marseille Université, CNRS, UMR 7303 TELEMME

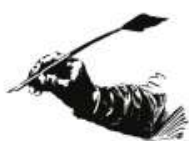

\section{Pau CASANELLAS}

Morir matando. El franquismo ante la práctica armada, 1968-1977, Madrid, Los Libros de la Catarata, 2014, 318 p.

El estudio de la historia política reciente de España es uno de los ámbitos de la historiografia que está experimentando una mayor expansión. Para demostrarlo basta nombrar las asociaciones profesionales, la calidad de las revistas especializadas, la cantidad de las novedades editoriales o los congresos que se celebran regularmente sobre aspectos generales o específicos del régimen franquista, la Transición o la democracia parlamentaria. No obstante, no todas las temáticas han sido investigadas por igual. Centrándonos exclusivamente en la historia política de la larga dictadura, lo cierto es que contamos con más trabajos sobre el devenir del antifranquismo que sobre los entresijos de la propia dictadura. Si bien no faltan obras sólidas sobre esto último, la mayoría tratan de la posguerra, especialmente de la represión sobre los vencidos de la Guerra Civil.

Por suerte, en los últimos años han aparecido algunas interesantes novedades editoriales que se adentran en otras fases y otros aspectos, como la evolución y el ocaso del régimen. Una de las más destacadas es Morir matando. El franquismo ante la práctica armada, la tesis doctoral del joven historiador Pau Casanellas (Universitat Autònoma de Barcelona), quien ya había dado muestras de sus progresos y su saber hacer en los artículos que ha ido publicando en revistas académicas como Historia del Presente, Tabula, Historia Social o Ayer.

Morir matando es un pormenorizado y bien escrito estudio sobre la política antiterrorista del régimen franquista, esto es, de su reacción ante el reto de la violencia política, durante el periodo comprendido entre dos fechas clave: 1968, marcado por la adopción de una estrategia armada por parte de un sector muy radicalizado de la oposición, y 1977, en cuyo mes de junio se celebraron las elecciones generales que dieron pie a la Transición democrática propiamente dicha. A lo largo de las 318 páginas de la obra, Casanellas realiza una análisis exhaustivo de las Fuerzas y Cuerpos de Seguridad del Estado, el desarrollo legislativo, la judicatura, el servicio secreto y las propuestas formuladas desde la esfera política para oponerse a la «lucha armada». Sin embargo, Morir matando no se limita a indagar en el aparato estatal, sino que también presta atención tanto a la interrelación de este con las organizaciones terroristas como a la represión en general y a su impacto sobre las fuerzas antifranquistas.

Un proyecto de tales características necesitaba de cimientos muy sólidos y, efectivamente, los tiene. Sobresale entre ellos el empleo de abundantes fuentes judiciales y policiales, la mayoría de las cuales permanecían inéditas. Se trata de una documentación custodiada en centros como el Archivo General de la Administración (Alcalá de Henares) y los archivos histórico-provinciales del País Vasco y Navarra. No obstante, no hay que pasar por alto 